\title{
Work in Progress: Using Videotelephony to Provide Independent Technical Critique of Student Capstone Projects
}

\author{
Dr. Walter W Schilling Jr., Milwaukee School of Engineering
}

Walter Schilling is an Associate Professor in the Software Engineering program at the Milwaukee School of Engineering in Milwaukee, Wis. He received his B.S.E.E. from Ohio Northern University and M.S.E.S. and Ph.D. from the University of Toledo. He worked for Ford Motor Company and Visteon as an Embedded Software Engineer for several years prior to returning for doctoral work. He has spent time at NASA Glenn Research Center in Cleveland, Ohio, and consulted for multiple embedded systems companies in the Midwest. In addition to one U.S. patent, Schilling has numerous publications in refereed international conferences and other journals. He received the Ohio Space Grant Consortium Doctoral Fellowship and has received awards from the IEEE Southeastern Michigan and IEEE Toledo Sections. He is a member of IEEE, IEEE Computer Society and ASEE. At MSOE, he coordinates courses in software quality assurance, software verication, software engineering practices, real time systems, and operating systems, as well as teaching embedded systems software.

\section{Dr. John K. Estell, Ohio Northern University}

John K. Estell is a Professor of Computer Engineering and Computer Science at Ohio Northern University. He received his $\mathrm{MS}$ and $\mathrm{PhD}$ degrees in computer science from the University of Illinois at UrbanaChampaign, and his BS in computer science and engineering from The University of Toledo. His areas of research include simplifying the outcomes assessment process, first-year engineering instruction, and the pedagogical aspects of writing computer games. John currently serves as Chair of the Computers in Education Division and was one of the principal authors of the Best Paper Rubric used for determining the Best Overall Conference Paper and Best Professional Interest Council (PIC) Papers for the ASEE Annual Conference. He is a past recipient of Best Paper awards from the Computers in Education, First-Year Programs, and Design in Engineering Education Divisions. Dr. Estell is an ABET Commissioner, Vice President of The Pledge of the Computing Professional, a Senior Member of IEEE, and a member of ACM, ASEE, Tau Beta Pi, Eta Kappa Nu, Phi Kappa Phi, and Upsilon Pi Epsilon.

\section{Dr. Khalid S. Al-Olimat P.E., Ohio Northern University}

Dr. Khalid S. Al-Olimat is professor and chair of the Electrical \& Computer Engineering and Computer Science Department at Ohio Northern University. He obtained his BS in Electrical Engineering from Far Eastern University in 1990, the MS in Manufacturing Engineering from Bradley University in 1994 and his $\mathrm{PhD}$ in Electrical Engineering from the University of Toledo in 1999. Dr. Al-Olimat is the recipient of Henry Horldt Outstanding Teacher Award in 2004. He is a senior member of IEEE and the chair of IEEE-Lima section. His areas of interest are power engineering, adaptive, fuzzy and intelligent control. Dr. Al-Olimat is a registered professional engineer in the State of Michigan. 


\title{
Work in Progress: Using Videotelephony to Provide Independent Technical Critique of Student Capstone Projects
}

\begin{abstract}
As part of the requirement for ABET accreditation, an engineering program is expected to have a curriculum culminating in a major design experience, commonly referred to as either a "senior design" or a "capstone" project, based on the knowledge and skills acquired in earlier course work. One challenge that programs face is providing appropriate technical and professional feedback to students on their capstone projects. For example, students may be working in an application domain in which the faculty member has limited knowledge, or may be using newer technologies that the faculty member has not used before. To overcome these problems, it is often advantageous for the team to partner with an industrial mentor. The industrial mentor can provide technical assistance to the project as well as provide impartial and unbiased feedback on the status of the project. However, this is not always feasible, as not all campuses are located in urban areas, and project stakeholders may not be local to the institution.

This work in progress article describes the first part of a two part project to overcome some of these problems. In this portion of the project, capstone teams work directly with an alumnus who serves as "External Industrial Reviewer" on the project using remote video conferencing. As the students complete significant milestones, deliverables are critiqued by External Industrial Reviewer who is impartial to the project. Students receive feedback on the deliverable, which can then be incorporated into future projects. This article describes the concept as well as provides a preliminary assessment of the technique.
\end{abstract}

\section{Introduction}

Managing capstone projects at small institutions represents a significant logistical challenge as, with a limited number of engineering faculty, the specific technical knowledge necessary to properly direct an industry-sponsored or cutting-edge capstone design experience might not be present. This problem may be further complicated if the institution is located in a rural area, as their students are often forced to work in physical isolation, their clients are not nearby, and travel constitutes an inconvenience. The College of Engineering at Ohio Northern University a private four-year institution located in the village of $\mathrm{Ada}, \mathrm{OH}$, exhibits these characteristics. There are approximately 450 students in the college, and the nearest major cities (i.e., those with a population of 100,000 or greater) are between one and two hours away from campus. While this isolated environment offers many advantages from an academic standpoint, it also poses many significant challenges. In the ECCS Department, comprised of approximately 140 students, one faculty member, the Senior Design Coordinator, is tasked with the coordination of all senior capstone projects while the remaining nine faculty members all serve as team 
advisors $^{1,2}$. Furthermore, there has been an increased emphasis on multidisciplinary projects, requiring the standardization and coordination of many elements of the capstone experience and fostering greater interaction with students and faculty in other departments ${ }^{3,4,5}$.

\section{Capstone Project Scope and Milestones}

The department solicits project proposals prior to mid-April of the junior year. A number of projects are sponsored and/or provided by external industrial clients, whereas other projects are proposed by faculty members of the department. Proposals are generally in the form of a one- or two-paragraph statement that identifies an opportunity or a need and puts forth a concept that can address that opportunity or need. All submitted project proposals are first reviewed in a department faculty meeting to ensure that they have an appropriate technical level of complexity. The approved project abstracts are then distributed to the junior students. Each student is asked to choose three or four project proposals and submit them in ranked order of preference. This feedback is reviewed by the faculty for their comments, after which the department chair and senior design coordinator assign students to appropriate project groups based on student capabilities, project needs, and placement preferences Each team is advised by a faculty member and students start interacting with their faculty project advisor prior to the end of the junior year.

The senior capstone experience consists of a year-long sequence of two courses; ECCS 4711 Senior Design 1 which is offered in fall semester; and ECCS 4721 Senior Design 2 which is offered in spring semester. Projects are completed in teams of between 3 and 5 students, and there are approximately 10 teams. All teams are required to meet on weekly basis with their faculty project advisor. There are two required oral presentations (the proposal presentation and project progress presentation) to be given before the Project Review Board (PRB), consisting of the faculty members of the department, and a submission of the written proposal during the duration of the first course. The PRB members evaluate the projects based on both the oral presentations and written report using specific rubrics. The senior design coordinator provides the industry mentor with the written proposal and the related rubric ahead of the occurrence of the teleconferencing (usually a week earlier). Both the PRB and the industry mentor provide suggestions to improve the quality of the design proposals.

In the second senior design course, student teams continue in the implementation phase, working closely with their advisors on their design project while employing all steps in the engineering design process in the production of a working prototype. Teams are required to submit a written progress report and give an oral presentation to the members of the PRB at the middle of the semester. This way, the department insures that there is sufficient time in the process for revisions to be made, thereby supporting the iterative nature of real-world design and make students better prepared for the college wide design showcase event on April. 
In the first week of April, student teams present their projects and working prototypes through poster session in the college design showcase. The posters are judged jointly by the members of Lima Section IEEE, the department's Program Working Groups (which includes the industry mentors), and other representatives from industry.

After the poster session, final touches are made to the projects and student teams focus on the documentation deliverables. Primary emphasis is placed on a professional quality written technical report, which includes detailed design documentation, and is graded by multiple faculty members. An oral presentation of their completed project to their peers and faculty is also a major course component. Finally, each team develops a web site for their project which serves as a document repository.

\section{Previous Work}

The management of capstone projects has been the topic of numerous papers, both at ASEE and other conferences. Since the adoption in 2000 by ABET of an outcomes-based assessment process, there has been an increased emphasis placed upon the quality of the capstone experience, as well as an increased emphasis on increasing the realism of the capstone experience.

Many authors have discussed mechanisms to improve the quality of capstone projects. Paliwal and Sepahpour ${ }^{6}$ discuss the addition of significant review activities by faculty members as a mechanism for improving the outcomes of the design experience. Green et al. ${ }^{7}$ talk in depth about the issues related to implementing an interdisciplinary senior design capstone experience, focusing on the need for faculty specific roles as well as appropriate team composition on the basis of technical skills and knowledge. Teng and Liu $^{8}$ discuss the managerial models which can be applied to capstone projects with industry collaboration. Fries et al. ${ }^{9}$ discuss the importance of working directly with a practicing engineer in industry on a routine basis.

\section{The Concept}

In industry, it is often required that a project undergo an independent review. When a project is independently reviewed, an outside expert is brought in to the project to examine the material and determine the quality of the work. In 2007, the National Research Council asserted that independent reviews are one of the means by which industrial firms become successful at project management and continue to stay that way ${ }^{10}$. 
Independent review processes have already been added into some capstone projects. Delaney ${ }^{11}$ reports on the advantages of having students independently reviewed on their capstone projects. In this case, the independent review focuses more on technical presentation than technical content, but there still is the element of independent review. McGinnis and Welch ${ }^{12}$ discuss how feedback from an industrial partner works when projects are sponsored by an external entity. However, not all projects have an industrial partner. Furthermore, in many cases the industrial partner only reviews the scheduling and project management aspects of the project, not the technical aspects of the project.

As has been stated previously, there are occasions where the faculty member who is assigned to mentor the design team may not have full knowledge of either the technology or the domain of the problem. This can be problematic, for if the students encounter difficulties, the faculty member may not have the appropriate depth of knowledge to provide adequate guidance. However, programs which have a strong working relationship with their industrial advisory board have a great resource available to them. Besides being a valuable means for being in touch with one's constituent groups as required by ABET, industrial advisory boards offer programs a mechanism for soliciting volunteers who are practicing engineers in industry. Often comprised of alumni, these advisory board members are more than willing to contribute the success of future students through active participation. To tap this resource, a new position was added to the capstone project organization chart: the external technical evaluator. As illustrated in Figure 1, the Senior Design Coordinator recruits an external technical evaluator from the program's industrial advisory board to the team, with an attempt to provide the best match between the needs of the projects and the technical expertise of the selected board member. This evaluator is tasked with providing a technical review of major project artifacts. The hypothesis being tested is that this approach will lead to increased technical quality of capstone design projects, increased professional quality of capstone design projects, and increased interaction with institutional alumni while creating minimal administrative overhead. 


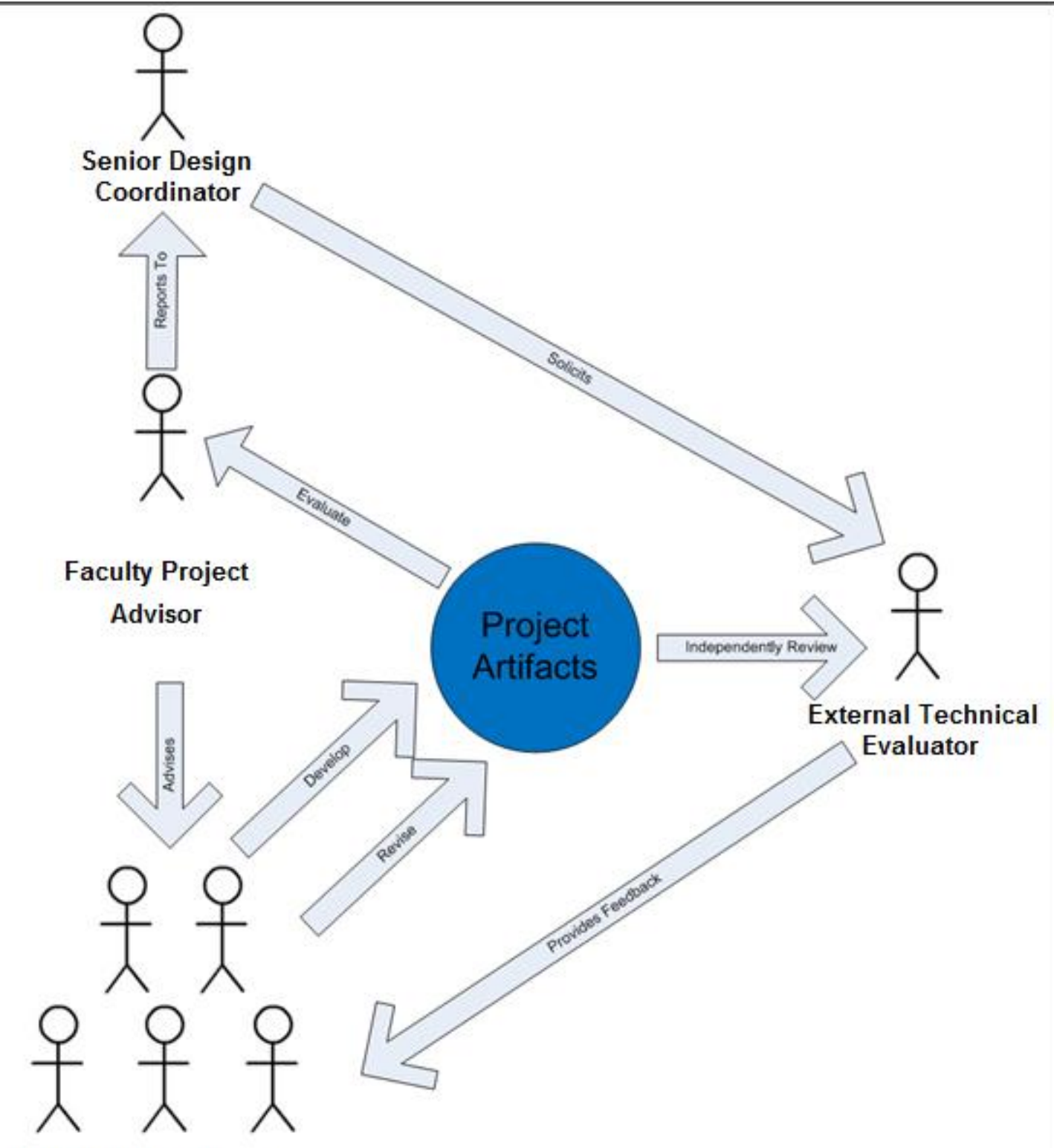

Capstone Design Team

Figure 1: Conceptual Roles

To be effective, the review process must attempt to minimize the amount of additional administrative overhead incurred by the project. Because of location and scheduling issues, reviews have been, and will continue to be, conducted entirely by Skype or Google Chat mechanisms, thereby replacing the need for face to face meetings. This also, in some regards, increases the realism of the process, for it is now common for large industrial companies to conduct major technical reviews of projects distributed amongst several geographically-diverse teams via teleconference. 


\section{Proof of Concept and Planned Assessment}

Due to the experimental nature of this initiative, students enrolled in the 2013-2014 capstone design sequence at Ohio Northern University were advised of the nature of the experiment and given the option to request an independent reviewer. Interested teams were required to obtain the concurrence of their capstone design advisor. For those teams that were chosen to participate, the capstone course instructor selected an external technical evaluator from the pool of volunteers from the ECCS Department's industrial advisory board. The remaining capstone design teams are being used as a control.

As each significant deliverable of the capstone design process is completed, the team reviews the deliverable with their faculty advisor using already established processes. However, the team also provides a copy of that deliverable to the external technical evaluator for critique. The team and the evaluator then arrange to meet via teleconferencing applications such as Google Chat. This allows the evaluator to provide technical feedback on the project while the team have the opportunity to hone their technical communication skills. Communications are limited to only one per significant deliverable to ensure that the role is not burdensome to either the external technical evaluator or the capstone design team, and the design team is free to either accept or reject the feedback as they see fit.

As of the time of publication, a thorough assessment of the technique has not yet been conducted, as the projects have not yet been completed. However, preliminary comments, as shown in Appendix B, have been favorable.

Following the completion of the 2013-2014 academic year, the effectiveness of this approach will be accessed, with the intent of up-scaling the approach if it is deemed to be successful. Thus, as of the time of drafting this article, detailed assessment results are not available. However, an assessment approach has been laid out which will involve a simple survey of the participants. The survey for the participating capstone design students is given in Appendix A; similar instruments will be developed to solicit input from the external technical evaluators and associated faculty advisors. In addition to the survey, the projects of the participating teams will be compared against the control group at the completion of the capstone process to try and ascertain if the projects which had external involvement ended up with either a higher quality project, a more complete project, and/or a more professionally polished project. Unfortunately, a purely objective measure may be difficult to obtain, given the extreme variability in capstone project content. 


\section{Future Plans}

If a favorable assessment of the first part of this project is obtained, then the second phase will be implemented. In the second phase of the project, external review will be a required aspect of capstone design projects, and all teams will be assigned an appropriate external technical reviewer. Additionally, instead of using synchronous video techniques, the reviews may shift to an asynchronous format. This asynchronous format will allow for the reviews to be directly included in the project portfolio. The evaluation will be conducted again, and a further comparison of the effectiveness of the technique will occur.

\section{Conclusions}

This article has presented a work in progress at Ohio Northern University, with the goal enhancing the quality of capstone design projects. Students are assigned an external technical reviewer from the program's industrial advisory committee, and this reviewer provides an independent assessment of the capstone deliverables. Students then use this independent feedback to improve their project. An assessment mechanism to determine the effectiveness of the approach has been presented, as well as an overview of the next phase of the project if the proof of concept is deemed to be successful. 


\section{Bibliography}

[1] "Assessment of the Results of External Independent Reviews for US Department of Energy Projects," National Research Council, 2007.

[2] K. Delaney, "Evaluating "Independent" Assessment of Capstone Projects by Mechanical Engineering Students in DIT," in Proceedings of Edulearn, Barcelona, 2011.

[3] K. Al-Olimat, "An Industry Sponsored Capstone Project: A Story of Success," in Proc. 2010 ASEE Annual Conference, Louisville, KY, 2010.

[4] J. K. Hurtig and J. K. Estell, "Truly Interdisciplinary: The ONU ECCS Senior Design Experience," in Proc. 2005 ASEE Annual Conference, Portland, OR, 2005.

[5] J. K. Hurtig and J. K. Estell, "A Common Framework for Diverse Capstone Experiences," in Proc. of the 2009 Frontiers in Education Conference, San Antonio, TX, 2009.

[6] J. K. Hurtig and J.-D. Yoder, "Lessons Learned in Implementing a Multi-disciplinary Senior Design Sequence," in Proc. 2005 ASEE Annual Conference, Portland, OR, 2005.

[7] J. K. Estell, D. Mikesell and J.-D. Yoder, "A Decade of Multidisciplinary Capstone Collaboration," in Proc. 2014 Capstone Design Conference, Columbus, OH, 2014.

[8] M. Paliwal and B. Sephahpour, "A Revised Approach for Better Implementation of Capstone Senior Design Projects," in Proc. 2012 ASEE Annual Conference, San Antonio, TX, 2012.

[9] M. Green, P. Leiffer, T. Hellmuth, R. Gonzalez and S. Ayers, "Effectively Implementing the Interdisciplinary Senior Design Experience: A Case Study and Conclusions," in Proc. 2007 ASEE Annual Conference, Honolulu, $\mathrm{HI}, 2007$.

[10] S. G. Teng and P. C.-H. Liu, "Collaborative Environments for Managing Industrial Projects," in Proc. 2003 ASEE Annual Conference, Nashville, TN, 2003.

[11] R. Fries, B. Cross and S. Morgan, "An Innovative Senior Capstone Design Course Integrating External Internships, In-Class Meetings, and Outcome Assessment," in Proc. 2010 ASEE Annual Conference, Louisville, KY, 2010.

[12] M. McGinnis and R. Welch, "Capstones with an Industrial Model," in Proc. 2010 ASEE Annual Conference, Louisville, KY, 2010. 


\section{Appendix A: Senior Project Industrial Peer Review Assessment Survey}

1) How much time did you spend working with your industrial reviewer?
a) None
b) 1 - 5 minutes
c) 6 - 10 minutes
d) $11-15$ minutes
e) $16-20$ minutes
f) $21-25$ minutes
g) 26 - 30 minutes
h) $31-35$ minutes
i) 36 - 40 minutes
j) 41 - 45 minutes
k) More than 45 minutes

2) How large was the artifact which your industrial reviewer reviewed?
a) No artifact was provided to the reviewer
b) 1 - 4 pages
c) 5 - 8 pages
d) 9 - 12 pages
e) 13 - 16 pages
f) $17-20$ pages
g) $21-24$ pages
h) More than 24 pages

3) How many major issues did your reviewer find in your artifact?
a) None
b) 1 - 2 issues
c) 3 - 4 issues
d) 5 - 6 issues
e) $7-8$ issues
f) 9 - 10 issues
g) more than 10 issues

4) How many minor or other simple issues did your reviewer find in your artifact?
a) None
b) $1-2$ issues
c) $3-4$ issues
d) 5 - 6 issues
e) $7-8$ issues
f) 9 - 10 issues
g) more than 10 issues

5) The review session with an industrial reviewer found defects which were not found by my senior design advisor.
a) yes
b) no

6) I found the review session by an industrial reviewer to be extremely useful.
a) strongly agree
b) agree
c) neutral
d) disagree
e) strongly disagree

7) I would highly recommend that future teams be able to have an industrial reviewer review their artifact as part of the senior design process.
a) Strongly agree
b) Agree
c) Neutral
d) Disagree
e) Strongly Disagree

8) Do you have any other comments on the industrial review process? 


\section{Appendix B: Sample Student Comments}

1. When we had our Skype meeting, Nick went over several things that were really helpful in making our paper better. He even touched on things we ourselves said we wanted to add but didn't change before he looked at it. This made it all the more reason to fix those issues. I thought getting feedback from Nick was great. I hope the ECCS department does this for senior's next year. I do wish the next time it is done, we had the groups that weren't presenting at the time wait outside so they don't distract the current team speaking with Nick. It would make it more comfortable for the presenting team.

2. I feel like the Skype conversation with Nick. For our project I feel he gave some pretty worthwhile advise and direction. It would have been nice to possibly have this conversation happen a little bit sooner rather than so close to the PRBs. I feel this could be a great requirement to add to the senior design process. I don't think it really adds too much work on the student's end and has the potential to be very beneficial.

3. I do believe our Skype session with Mr. V. was a good feedback mechanism for our Sr. Design project. Since Mr. V. has almost 10 years of industry related experience, he was able to point out if we were "dreaming too big" or being unrealistic in some of our proposed deliverables for the final presentation. Basically, he helped us in narrowing the scope of our project by encouraging us to think more in short term success of our prototype, rather than what we ideally want to create.

4. I did think the Skype conversation with Mr. V. was a good idea. Personally, I think he did make some good points about our project, but unfortunately most of them went against what our advisor was wanting so we did not get to incorporate many of his ideas. But, it was nice to get an outsider's opinion on the project. I think it is a good idea to use this in the future. It didn't take that long to actually have the conversation, and the information discussed could be valuable to future groups.

5. In our experience with the professional in the field webcam chat, the advice did not seem to do anything productive for the project. In fact, he was discouraging with his opinionated concerns of even pursuing this capstone project that we were trying to accomplish. It seemed as if he did not read our paper in its entirety or did not completely understand the outlined goals. On several occasions he would try and convince us to do something either too complicated or attempt a project that would take too much time. He was quoted as saying "I don't buy it, its not going to work." However, aside from the negative comments he did help with paper formatting and information that needed to be included.

As a group it was agreed that there shouldn't be just be one "catch-all" professional that helps all the groups because although he may be intelligent in a couple specific fields he does not necessarily have expertise to criticize our type of project. Instead, this should be done independently by each group to obtain a professional in the field more involved with their respective topics for better feedback. It is also recommended to not be a mandatory assignment because the opinions of an outside source should not reflect on us as a grade, it should be a beneficial experience, not a potentially harmful one. We thought that by doing a short, elevator pitch of the project and having question period afterwards would provide better knowledge for both ends and could clear up communication issues. Since it was early enough in the semester the 
proposals were not very detailed anyways, so he wouldn't need all of the extra information such as planning, budget expenses, or literature review. Reading through all of the papers by the different capstone groups takes too much time and they have already been critiqued multiple times by other professors. This would help get straight to the point of the goals and objectives of our project while minimizing confusion. The question period, open to both parties, would be an opportunity to learn more about the project and possibilities rather than just listening to his opinions that were formed while reading a drafted proposal. 